\title{
The Extended Pterional Approach and \\ Microsurgery Resection for \\ Craniopharyngiomas, Operative Nuances and \\ Results: A Series of 29 Patients
}

\section{Craniotomia pterional estendida e remoção microcirúrgica dos craniofaringiomas, nuances cirúrgicas e resultados: uma série de 29 pacientes}

\author{
Jose Carlos Lynch ${ }^{1}$ Celestino Pereira ${ }^{1}$ Valérie Manicacci ${ }^{1} \quad$ Mariangela Gonçalves $^{1} \quad$ Leonardo Welling $^{1}$ \\ Rudy Lenk ${ }^{1}$ \\ ${ }^{1}$ Department of Neurosurgery, Hospital Federal dos Servidores do \\ Estado (HFSE), Rio de Janeiro, Rio de Janeiro, Brazil \\ Arq Bras Neurocir 2016;35:197-206. \\ Address for correspondence José Carlos Lynch, MD, Centro de \\ Neurocirurgia das Américas, Rua Jardim Botânico, 600 \# 605 ZIP: \\ 22461-000 Rio de Janeiro, RJ, Brasil \\ (e-mail: cneuroamericas@uol.com.br; jclynch@globo.com).
}

\section{Abstract \\ Keywords \\ - extended pterional approach craniopharyngiomas \\ - microsurgery \\ - intracranial tumors \\ - radical resection \\ - tumor recurrence}

Objective The aim of this paper is to observe if the extended pterional approach for the removal of craniopharyngiomas is safe and effective. The mortality, morbidity, and recurrence rates are presented and discussed.

Method This is a retrospective analysis of 29 craniopharyngioma patients who underwent surgery between January 1988 and December 2014 at the Department of Neurosurgery of the Hospital Federal dos Servidores do Estado, Rio de Janeiro, Brazil. The charts, operative reports and imaging studies were reviewed.

Results We identified 17 males (58.6\%) and 12 females (41.3\%) ranging in age from 0.6 to 84 years (mean 57.4 years). Thirteen (44.8\%) patients were infants or adolescents. Surgical mortality occurred in one patient (3.4\%). Gross total tumor removal was achieved in $15(51.7 \%)$ patients. The median follow-up time was 7.1 years. Conclusion The extended pterional approach provides adequate access to craniopharyngiomas, and the majority of lesions could be totally removed, with a low mortality rate, but the best treatment for craniopharyngiomas remains controversial. received

April 29, 2016

accepted

June 22, 2016

published online

August 9, 2016
DOI http://dx.doi.org/

10.1055/s-0036-1586761. ISSN 0103-5355.
Copyright $@ 2016$ by Thieme Publicações License terms

Ltda, Rio de Janeiro, Brazil

(c) (i) $\ominus$ (\$) 


\author{
Resumo \\ Palavras-chave \\ - acesso pterional \\ estendido \\ - craniofaringiomas \\ - microcirurgia \\ - tumores \\ intracranianos \\ - remoção radical \\ - recorrência tumoral \\ Objetivo Observar se a craniotomia pterional estendida é uma técnica segura e \\ efetiva. \\ Método É um estudo retrospectivo de 29 pacientes com craniofaringiomas que \\ foram submetidos a craniotomia pterional estendida entre 1988 e 2014. As imagens e \\ os prontuários foram analisados. \\ Resultados Esse grupo é composto por 17 homens (58,6\%) e 12 mulheres (41,3\%), e a \\ idade variou de 0,6 a 84 anos (media 57,4 anos). Treze (44,8\%) pacientes eram crianças \\ ou adolescentes. A remoção total da lesão ocorreu em 15 (51,7\%) indivíduos. A \\ mortalidade cirúrgica: um paciente (3,4\%). O follow-up médio é de 7,1 anos. \\ Conclusão A craniotomia pterional estendida permitiu a remoção total da lesão na \\ maioria dos pacientes, com baixa mortalidade, porém o melhor tratamento para o \\ craniofaringioma ainda gera muita controvérsia.
}

\section{Introduction}

The overall incidence of craniopharyngiomas (CPs) is of 0.13 per 100,000 person/year. A bimodal distribution by age was noted with peak incidence rates in children and adolescents (aged 5-14 years) and in adults (aged 65-74 years). ${ }^{1}$ Craniopharyngiomas arise typically in the infundibulum-hypophyseal area, occupying frequently the suprasellar cisterns. Although histologically benign, the lesion's potential for adhesion to the optic chiasm $(\mathrm{OCh})$ and hypothalamus can lead to significant deficits.

The treatment of craniopharyngiomas is one of the most challenging neurosurgical problems, and a controversial debate has been going on for years, which has not been settled to date: should the neurosurgeon promote gross total tumor removal (GTTR), which can cure the patient but result in unwarranted neurological deficit, or should GTTR be avoided, and a safer, subtotal tumor removal (STR) be performed instead? $?^{2-25}$

Our review found a paucity of significant information in Brazil addressing specifically the surgical treatment of CPs. ${ }^{3}$ This fact encouraged us to reveal our operative strategy and surgical technique.

\section{Method}

\section{Data Collection}

A retrospective study at a single institution was performed to review and evaluate a cohort of $29 \mathrm{CP}$ patients who underwent surgery between January 1986 and December 2014 at the Department of Neurosurgery of the Hospital Federal dos Servidores do Estado (HFSE), Rio de Janeiro. Two of the authors (J.C.L and C.E.P) performed all of the surgical procedures. The charts, pre and postoperative imaging, and pathological reports of the patients were retrospectively reviewed to ascertain the diagnosis of $\mathrm{CP}$, thereby creating a database from which information pertinent to the present study was collected. The limitations of this study are inherent to its retrospective nature. The need for informed consent was waived due to the retrospective character of the report. A detailed endocrinological evaluation is beyond the scope of the current study. Computed tomography (CT) and magnetic resonance imaging (MRI) scans were reviewed with the Radiology Department. Control postoperative imaging was performed within the first 72 hours after surgery to document the extent of the resection and of the postoperative changes. The intraoperative videos and/or photos of 25 patients were analyzed for nuances of the microsurgical technique. In each case, the degree of tumor removal was determined using a combination of the surgeon's assessment and postoperative images.

\section{Follow-up}

The first clinic visit was $\sim 15$ days after hospital discharge, and then at 2 and 6 months, and thereafter patients were reexamined at 1 -year intervals. Patients who were alive were contacted for imaging and clinic visits, or at least interviewed by telephone to describe their symptoms referable to the neurological status. The Glasgow Outcome Scale (GOS) defined the outcome. The median follow-up time was 7.7 years (range: 1 to 23 years).

\section{Neurosurgical Approach: The Extended Pterional Craniotomy}

The same approach and microsurgery technique was used in all cases, following these general steps: under endotracheal general anesthesia, the patient's head is secured in the Mayfield three-point fixation system. Due to risk of air embolism, a central venous catheter is placed in all patients to allow air aspiration. An arterial line is placed in the radial artery. If needed, arterial hypotension for bleeding controls is obtained. Routine antibiotics, dexamethasone, antiseizure prophylaxis and mannitol were routinely used. The patient is placed in supine position with 30 degrees of elevation and 30 degrees of rotation of the head for the contralateral side and deflation of the head towards the floor. The procedure was initiated with the use of a $2.5 \mathrm{X}$ surgical loupe and co-axial lighting for soft tissue incision and bone work. The patient is secured with a large tape in the operating table to allow table rotation to the right or to the left, and elevation or depression of the head. These simple maneuvers, associated with multiple microscope angulations, enhance the exposure, 
expanding the operative field and decreasing the amount of bone removed.

A frontotemporal skin incision was initiated $\sim 1 \mathrm{~cm}$ anterior to the tragus, ascending from the zygomatic arch, staying behind the hairline and extending to the midline. Hemostasis is obtained with hemostatic clamps; the scalp flap is turned anteriously and maintained in position with the help of several rubber bands. The superficial temporal artery and the frontalis branches of the facial nerve are preserved through intrafascial dissection. The temporalis muscle and fascia are sectioned in the projection of the skin incision, detached from their insertion and rotated anteriously, exposing the junction of the zygomatic, sphenoidal, and frontal bones. The periosteum is incised, dissected and reflected over the scalp and muscular flap.

One burr hole is obtained with a high-speed drill at the superior-lateral aspect of the orbital rim, above the intersection of the zygomatic bone and the supraorbital ridge. The craniotomy is performed with a power craniotome from the burr hole, extending anteriorly, touting the orbital rim, until and $\sim 2 \mathrm{~cm}$ of the entrance of the frontal sinus. If possible, the frontal sinus is avoided during the frontal extension of the craniotomy; if the frontal sinus is entered, the mucosa is removed and occluded with a temporalis muscle graft, then a sharp turn is made posteriorly, and the cut is extended behind the coronal suture. Another sharp turn is made inferiorly and then anteriorly, and extended towards the burr hole. The bone flap is removed from the wound. To improve access to the basal cisterns and decrease contusion on the brain parenchyma, the lesser wing of the sphenoid bone is flattened with a high-speed drill, using cold saline irrigation to avoid heat injury, until the meningo-orbital band is fully exposed and then removed using a fine rongeur. The bone wedges are carefully waxed. The optic canal is not routinely opened in cases of CP.

A frontotemporal curvilinear opening is made in the dura mater over the Sylvian fissure, and a second incision is directed towards the falciform ligament. The dural edges were tented up.

In $27(93.1 \%)$ of the patients, we elected right side craniotomy because the 2 surgeons involved in this series are right-handed, and right side craniotomy improves the maneuverability of the surgical instruments. In two patients we decided for a left side craniotomy because the tumors were huge and beside the suprasellar location; they spread deep towards the left Sylvian fissure.

\section{Microsurgery Techniques}

Exposing the tumor: the operative microscope is introduced in the surgical field, and the procedure is done with a magnification that varies from to 10 to 16 times. Moist cotton pads are placed over the frontal lobe and left there. The arachnoid of the Sylvian fissure and the basal cisterns are widely opened with micro scissors to allow cerebral spinal fluid (CSF) release, and with brain relaxation obtained, at this point the frontal and temporal lobes tend to fall apart spontaneously. The ipsilateral olfactory nerve, optic nerve $(\mathrm{ON})$ and the internal carotid artery (ICA) are identified and preserved. Opening the arachnoid of the carotid cistern and sequentially over the optic nerves exposes the tumor.
In cases of a postfixed type of optic chiasm (OCh), the OCh is displaced posteriorly and superiorly, creating a wide working space in the sub-chiasmatic and antero-chiasmatic areas. At that point, the high magnification provided by the operating microscope proved particularly beneficial. Several craniopharyngiomas contain cystic portions, and aspiration of the cysts is the first step, because this provides additional room for dissection. During the operation, copious irrigation was provided, and cotton pads were placed around the exposed area to reduce the spillage of irritating cyst content into the brain parenchyma: this has been associated with postoperative chemical meningitis. Debulking the tumor: the tumor capsule is teased beteween the ONs penetrated, and progressively debulked from within; this maneuver will mobilize the mass and allow the identification of the surrounding cerebrovascular structures. A rigorous hemostasis is obtained throughout the procedure using bipolar forceps to keep the field bloodless. Fine vessels travelling on the tumor surface are coagulated under saline irrigation and sharply severed. As the surgeon gradually internally decompresses the tumor, the central part of the suprasellar portion of the tumor is removed using nibble away removal techniques, widening the interoptic space and bringing the contralateral suboptic part into view. Dissecting and removing the tumor: close attention is paid to respect the arachnoid plane at the tumor brain interface, which facilitates GTTR and minimizes pial vessel and cortex injury. The tumor is sharply dissected from the medial side of the contralateral $\mathrm{ON}$, preserving its vasculature. Once the greater part of the suprasellar tumor has been removed, CSF pulsation pushes the upper part of the $\mathrm{CP}$ to the empty suprasellar space, and the capsule can be gently pulled downwards and peeled off from the under surface of the third ventricle. Tenacious adherence to the hypothalamus is sharply sectioned, mobilized and removed from the surgical field with cupped forceps. Sharp dissection continues circumferentially around the tumor capsule, which is released from the inferior aspect of the chiasm. Intrasellar tumors were carefully extracted with angled ring curettes. Parasellar tumor extensions were accessed with this approach, and were removed laterally to the $\mathrm{ON}$ and medially to the ICA through the optic-carotid triangle. Transection of the superior Sylvian veins and posterior retraction of the temporal pole enhance the access to the carotid oculomotor triangles, allowing the dissection of tumors extending behind the Clivus into the superior aspect of the posterior fossa (-Fig. 1).

In the prefixed type of $\mathrm{OCH}$, we use the trans-lamina terminalis route. In this situation, the lamina terminalis is fenestrated, providing direct access to the $\mathrm{CP}$ located in the retrochiasmatic space or involving the third ventricle (-Fig. 2 and -Fig. 3 ).

Small perforating arteries arising from the anterior communicating, posterior communicating, and branches from the anterior choroidal and thalamus perforating artery, as well as the proximal ICA frequently adhere to the tumor capsule, as they course toward the optic chiasm and anterior perforating substance. This close anatomic relationship with vascular structures is also an important factor that limits the extent of surgical resectability.

Only in cases in which the stalk is involved by the tumor is it justified to resect it, but frequently the stalk cannot be 


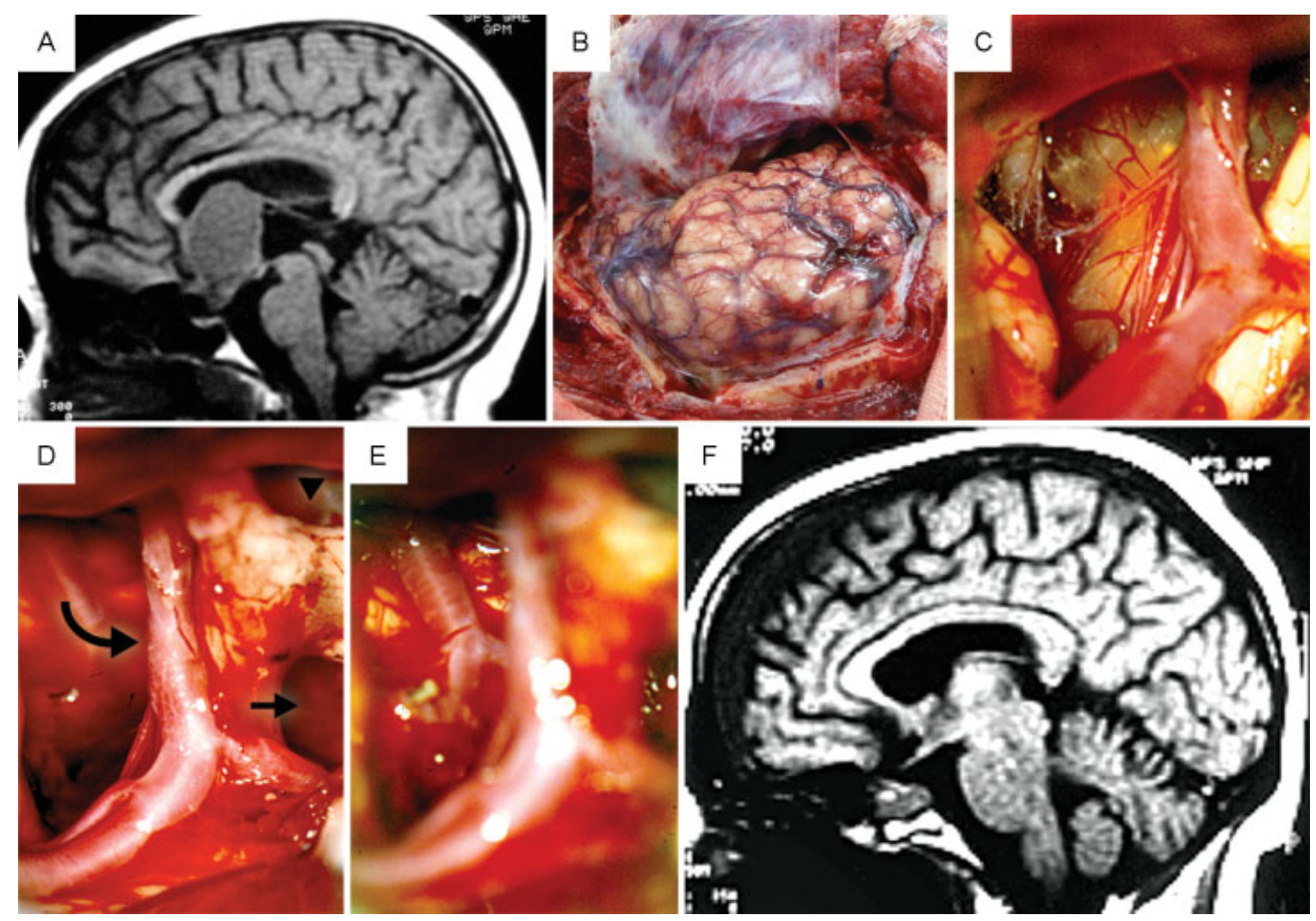

Fig. 1 (A) Sagittal T1-weighted MRI showing a giant craniopharyngioma with intraventricular extension. (B) Left extended pterional craniotomy. (C) Initial surgical photograph revealing a cystic-solid craniopharyngioma beneath the optic nerve and optic chiasm, with calcium deposits along the tumoral capsule. (D) The craniopharyngioma was removed through the carotid oculomotor triangle (curve arrow), the interoptic space (straight arrow) and the lamina terminalis (arrowhead). (E) After gross total tumor removal, the basilar artery came clearly into view. (F) Postoperative MRI confirming the gross total tumor removal.

clearly identified. Gross total tumor removal is always attempted, but whenever dissection of the tumor from the hypothalamus, perforating branches, could entail risk of damage, we left a rim of tumor attached to those structures (-Fig. 4). The extended pterional transsylvian approach provides an anterior view between the ONs, as well as a lateral view through the carotid cistern (- Fig. 1).

Inspection of the tumor bed is then achieved for verification of the extent of the tumor resection and oozing. The dura is closed primarily or with a pericranial free graft. The bone flap is secured with mini plates. The superficial planes are sutured in three layers. Postoperatively, all patients were cared for in the ICU before returning to the ward.

The transcallosal approach was reserved for 4 patients (13.7\%) with large third ventricle CPs that abut the Monro foramina. Intra and suprasellar sub-diaphragmatic CPs are best operated using the transsphenoidal approach. ${ }^{3,4,9,18,19,21,26-29}$ We did not include our transsphenoidal cases in this report.

\section{Results}

\section{Clinical Presentation and Pathology Report}

In this series, there were 17 (58.6\%) males and 12 (41.3\%) females. Their ages varied from 0.6 to 83 years (an average of
28.9 years). Thirteen patients were under 18 years old (44.8\%). Preoperative visual function revealed amaurosis (uni or bilateral) in 11 patients (37.9\%), visual decline in 10 patients (34.4\%), photophobia in 1 patient (3.4\%), quadrantopsia in 1 patient (3.4\%), and bitemporal hemianopsia in 4 patients (17.7\%). Fundoscopy revealed papilledema in 7 patients (24.1\%), and optic atrophy in 10 patients (34.4\%). Endocrinological findings revealed hypogonadism in 10 patients (34.4\%), hypothyroidism in 1 patient (3.4\%), Cushing in 1 patient (3.4\%), and adrenal insufficiency in 1 patient (3.4\%). Histopathologically, craniopharyngiomas are classified into two types: adamantinomatous and papillary craniopharyngiomas. The Department of Pathology at Hospital Federal dos Servidores do Estado performed the histological evaluation that revealed $2(15.3 \%)$ cases of the adamantinomatous type and 27 cases of papillary craniopharyngioma. The demographic and clinical profiles of the patients are summarized in -Table $\mathbf{1}$.

\section{Neuroimaging}

All patients underwent a preoperative CT and/or MRI. Fifteen CPs (51.7\%) showed calcifications, and in 3 of them the calcifications were of the heavy type. Sixteen (55.2\%) were predominantly cystic, and 13 were solid (44.8\%). Obstructive hydrocephalus was diagnosed in $8(27.5 \%)$ individuals. Tumor characteristics are summarized in -Table 2 . 

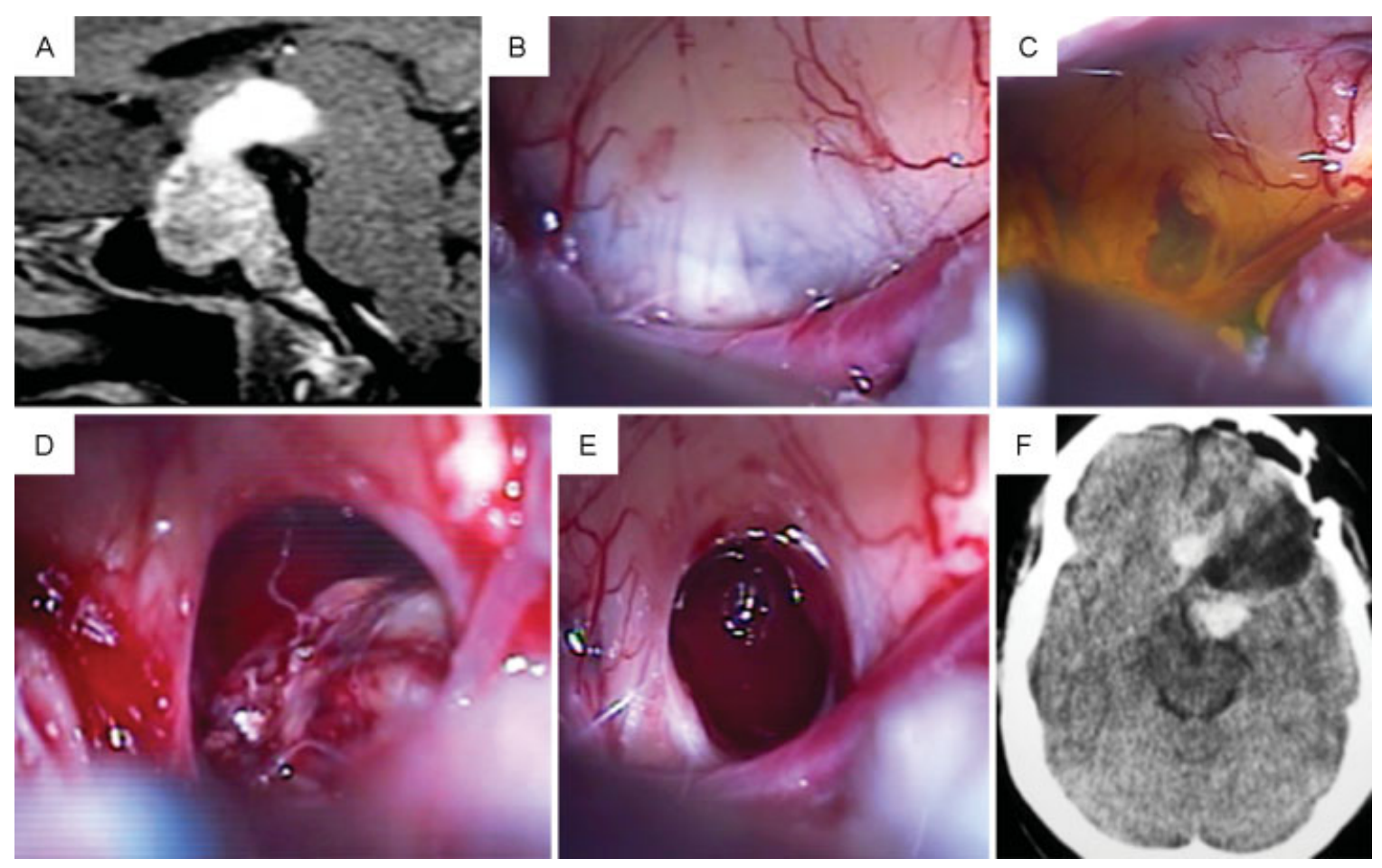

Fig. 2 (A) Sagittal Preoperative MRI images demonstrate a giant, complex craniopharyngioma, with extension into the third ventricle. (B) Intraoperative photograph obtained from a right side approach: the lesion can be seen underneath the ultrathin lamina terminalis. (C) The lamina terminalis is opened and a xanthochromic liquid leaked spontaneously. (D) The craniopharyngioma is being dissected and progressive mobilized. (E) After gross total tumor removal, the third ventricle is visualized free of tumor, the optic chiasma recovers its original position, and the interoptic space becomes widened. (F) Postoperative CT scans confirming gross total tumor removal and showing postoperative changes.

\section{Mortality, Morbidity, Radiotherapy, Extension of Resection and Recurrence}

The surgical mortality, defined as death within 30 days of surgery, was of $3.4 \%$ (one patient). The patient died of an untreatable electrolyte imbalance on the third postoperative day. The overall mortality of this series with a mean followup of 7.1 years was of $17.2 \%$ (5 patients). At our hospital, adjuvant external radiation therapy was applied during the postoperative course for 6 patients who underwent STR. Five individuals underwent a course of radiotherapy after tumor recurrence. A total dose of $54 \mathrm{~Gy}$ with $1.8 \mathrm{~Gy} /$ fraction in opposed lateral 3 portals was administered in 8 patients. Three children with recurrence were treated with conformal radiotherapy (RT) (54-55.8 Gy). Two patients were treated using intracystic bleomycin. Hypothalamic obesity was detected in four children. GTTR was achieved in 15 (51.7\%) patients. We observed recurrence in 15 (51.7\%) patients. Excellent or good outcomes (GOS 5 or GOS 4) were achieved in 18 (62.0\%) patients in this sample. Surgery on giant CPs (more than $4 \mathrm{~cm}$ at the largest diameter) has been associated with high mortality and postoperative morbidity rates, decreased extent of resection, and high rates of tumor recurrence. In our series, 18 (62\%) patients presented with giant CPs. Panhypopituitarism was observed in 11 patients (37.9\%). Diabetes insipidus occurred in 14 (48.2\%) patients. Postoperatively, 25 patients (86.1\%) needed hormone replacement for at least one hypothalamic-pituitary axis. (-Table 3). The literature in English was summarized for comparison in - Tables 4 and 5.

\section{Discussion}

\section{Management}

\section{Surgical Approaches and Microsurgical Techniques}

The best surgery strategy for CP has been debated for a long time. Various approaches have been described in the literature, including the pterional, 2,3,10,15,16,20 uni or bilateral sub frontal, 5,6,16 endoscopic endonasal 9,18,19,26-29 and cranial base approaches. ${ }^{12}$ The surgical technique presented here is modified from one described earlier by Yasargil et al. 2,3,15,20

The extended pterional approach has several advantages: it provides the shortest distance to the sellae turcicae, the early release of CSF from the basal cisterns, and it allows brain relaxation and minimizes frontal lobe retraction. The extended pterional transsylvian approach provides an anterior view between the ONs, as well as a lateral view through the carotid cistern ( - Fig. 1). Early exposure of the ON and Och provides protection of the visual system. The identification of the internal carotid artery improves the ability to dissect the anterior cerebral artery and its branches, allowing the protection of these vessels. ${ }^{2,3,15,20}$ This variation of the classic pterional craniotomy used in this series, possibility access through the sub fontal route besides the usual antero lateral view (-Fig. 1 B). It provides adequate access to CPS and allows for a wider operative field that is particularly important in cases of the retro-chiasmatic type. It also allows safe neurovascular dissection and facilitates GTTR. The 

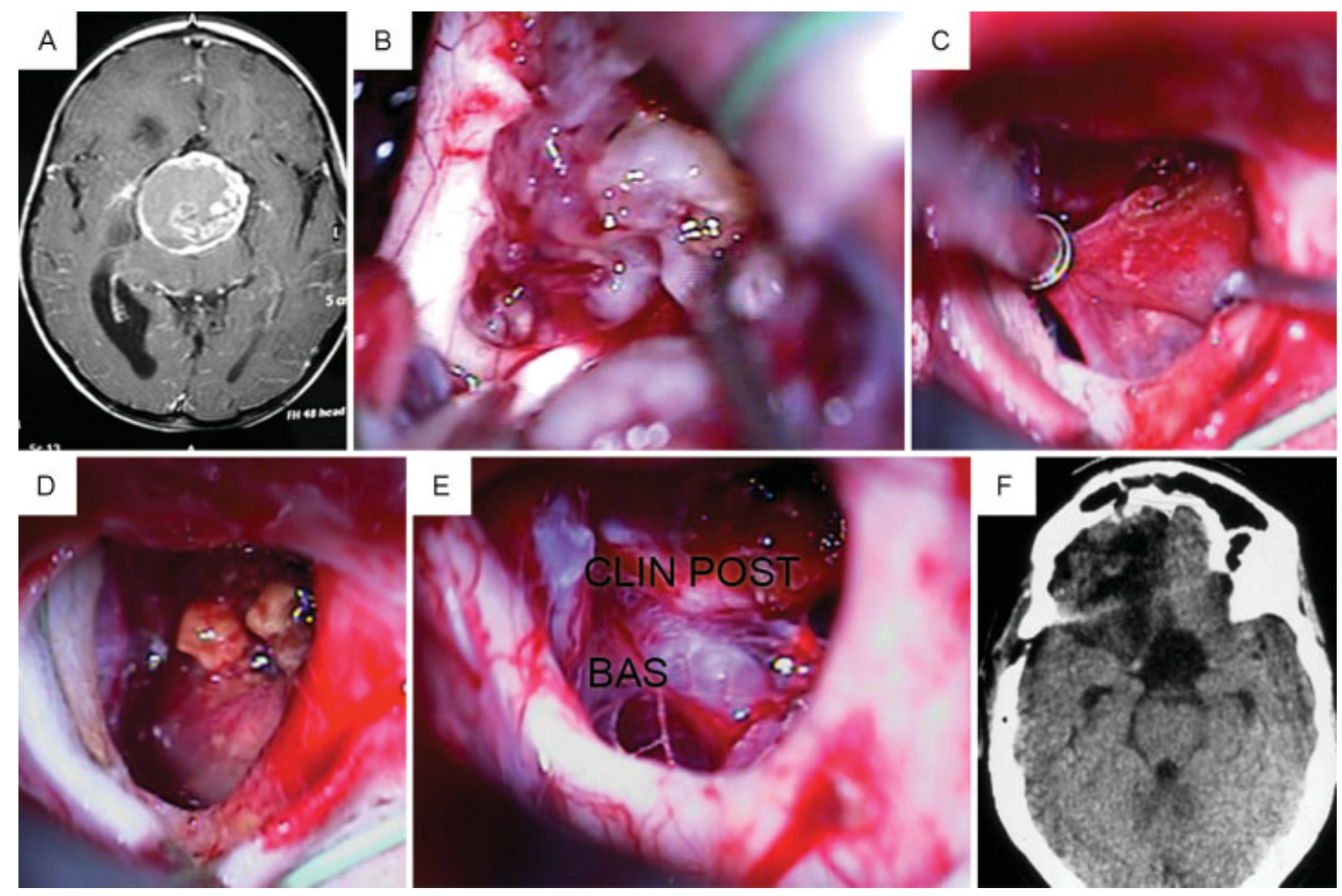

Fig. 3 (A) Contrast-enhanced MRI showing a large solid suprasellar craniopharyngioma projecting into the posterior fossa. (B) The tumor is being dissected and removed from the suprasellar space. (C) The capsule is gently dissected, mobilized medially, and removed from underneath the right optic nerve. (D) Tumor calcifications. (E) The dorsum sellae, the opposite internal carotid artery and the basilar artery are revealed after gross total tumor removal. (F) Postoperative CT showing GTR.

disadvantage of this approach lies on the fact that it is difficult to establish adequate visualization for the under surface of the ipsilateral ON and $\mathrm{CH}$. But shifting the surgical microscope medial and performing a lateral tilt of the operative table, we can partially circumvent this problem. This surgical nuance technique was not published before.

Several authors claimed that the frontal, lateral and pterional approaches provide remarkable improvement compared with the bifrontal approach., ${ }^{2,3,8,10,15,19}$ To decrease tumor recurrence, some authors recommend cranial base approaches, such as uni or bilateral orbital osteotomy, and cranial base drilling and reconstruction. Recently, Pernezky and Reisch, ${ }^{31}$ Fatemi et $\mathrm{al}^{32}$ and Wilson et $\mathrm{al}^{33}$ described the supra orbital approach (SOA). They stated that the SOA offers a simplified trajectory to $\mathrm{CP}$ and provides excellent access for optic apparatus decompression. The association of endoscopy is helpful to visualize hidden tumor remnants and maximize safe tumor removal. Compared with traditional craniotomies, the major limitation of the supraorbital approach is a narrow surgical corridor. Endoscopic endonasal surgery, supported by recent technological advancements, has been used increasingly over the last decade as an alternative approach to craniopharyngiomas. Most of the advantages of the endonasal endoscopic technique are obtained during tumor dissection and removal from the retro-chiasmatic area and in the third ventricle. This is because these regions, when approached from below, are in the direct surgical trajectory. ${ }^{9,18,19,26-29}$ These minimally invasive approaches require training that can only be obtained in high-volume centers, and therefore these approaches cannot be generalized to the whole neurosurgical community. Further follow-up is needed to assess the longterm efficacy of these approaches. ( $\mathbf{-}$ Tables $\mathbf{4}$ and $\mathbf{5}$ )

The demographic characteristics of the patients in this series did not influence the results.

\section{Extension of Resection Dilemma and Recurrence}

Because of the tendency for CP to recur, GTTR with the preservation of neurological function is the ideal treatment, resulting in the highest rates of recurrence-free survival and preserved quality of life (QoL). In the literature, GTTR rates range between $6-90 \%{ }^{2,4-8,12,13,15,16,20-22,24}$ In this current series, we achieved GTTR in 15 patients (51.7\%), which seems in agreement with the standard results reported in the literature (-Table 1). Gross total tumor removal is always attempted, but whenever dissection of the tumor from the hypothalamus and the perforating branches could entail risk of damage, we left a rim of tumor attached to those structures (-Fig. 4).

But GTTR could be dangerous for some patients and difficult to achieve because these tumors are critically located, and there may be adherence or even encasement of vital structures by the tumor. If the surgeon persists with any attempt to remove every last residual lesion to achieve the 


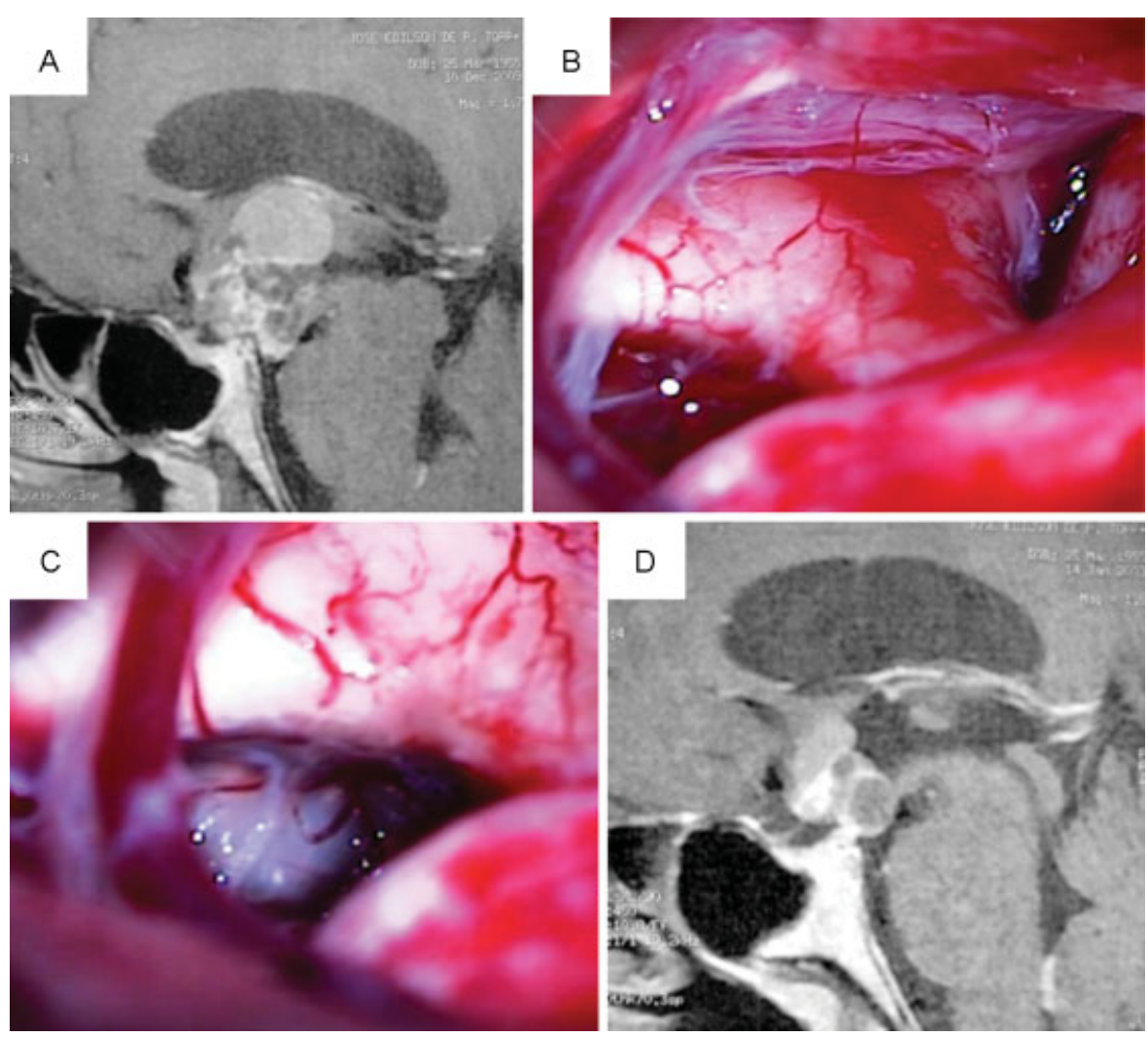

Fig. 4 (A) Sagittal preoperative contrast-enhanced MRI in a 43-year-old man showing a suprasellar and retro-chiasmatic craniopharyngioma. (B) With the right approach, the prefixed type of optic chiasma is revealed. The anterior communicating artery across the surgical field over the optic nerve. (C) Operative photographs of the right optic-carotid space, revealing the craniopharyngioma under the optic chiasma. (D) Postoperative contrast-enhanced MRI revealing a subtotal resection.

cure of the patient, it could result in an unwarranted hypothalamus lesion or injury in the perforating branches, thus preventing a safe radical removal. On diagnosis, many CPs are already large or giant, and frequently have extended into multiple anatomic compartments. Several authors reported increasing tumor size to portend higher rates of incomplete resection, higher rates of surgical morbidity, and an increased risk of recurrent disease. ${ }^{2,4,8,12,13,15,16,22}$

For these reasons, many authors recommend that GTTR should be avoided to decrease mortality and morbidity. ${ }^{10,11,13,23,25,30,31,33}$

Table 1 Characteristics of 29 patients with craniopharyngiomas

\begin{tabular}{|l|l|}
\hline Age at treatment 0.6-84 years (mean: 28.9 years) \\
\hline Under 18 years & $13(44.8 \%)$ \\
\hline Male & $17(58.6 \%)$ \\
\hline Female & $12(41.3 \%)$ \\
\hline Clinical - neurological picture & $22(75.8 \%)$ \\
\hline Visual deficit & $18(62.5 \%)$ \\
\hline Headache & $12(41.3 \%)$ \\
\hline Endocrinological deficit & $4(13.7 \%)$ \\
\hline Behavioral change &
\end{tabular}

Note: More than one symptom may occur in the same patient.
Others advocate a safer STR followed by radiation therapy. ${ }^{4,10,11,13,30-34}$ But STR creates conditions for recurrences, and repeated operations can prove even more difficult. The recurrence rate after STR has been reported at 7$75 \%$. $2,4,5,10,13,20-22$

Table 2 Tumor characteristics

\begin{tabular}{|l|l|}
\hline Calcification & $-15(48.2 \%)$ \\
\hline Suprasellar & $-18(62.0 \%)$ \\
\hline Adherent Hipothalamus & $-14(48.2 \%)$ \\
\hline Adherent CH and NO & $-10(34.4 \%)$ \\
\hline Inside third ventricle & $-18(62 \%)$ \\
\hline Hydrocephalus & $-8(27 \%)$ \\
\hline Cystic & $-16(55.1 \%)$ \\
\hline Solid & $-14(48.2 \%)$ \\
\hline Retro-chiasmatic & $-11(37.9 \%)$ \\
\hline Adherent third ventricle floor & $-18(62 \%)$ \\
\hline Adherent CA and ACoA & $-4(13.7 \%)$ \\
\hline Large or giant & $-18(62 \%)$ \\
\hline
\end{tabular}

Abbreviations: $\mathrm{ACoA}$, anterior communicating artery; $\mathrm{CA}$, carotid artery.

Note: Patients may present more than one tumor characteristic. 
Table 3 Clinical outcome

\begin{tabular}{|l|l|}
\hline Surgical mortality & $1(3.4 \%)$ \\
\hline CSF fistula & $1(3.4 \%)$ \\
\hline Panhypopituitarism & $11(37.9 \%)$ \\
\hline Panhypopituitarism plus DI & $14(48.2 \%)$ \\
\hline GTTR & $15(51.7 \%)$ \\
\hline Follow-up & $\begin{array}{l}1 \text { to } 23 \text { years } \\
\text { (mean }=7.1 \text { years) }\end{array}$ \\
\hline Lost follow-up & $7(24.1 \%)$ \\
\hline Radiotherapy & $11(37.9 \%)$ \\
\hline Recurrence & $15(51.7 \%)$ \\
\hline Last Outcome & \\
\hline GOS 5 & $41.1 \%$ \\
\hline GOS 4 & $20.6 \%$ \\
\hline GOS 3 & $8.6 \%$ \\
\hline GOS 2 & $8.6 \%$ \\
\hline GOS 1 & $20.7 \%$ \\
\hline
\end{tabular}

Abbreviations: CSF, cerebral spinal fluid; DI, diabetes insipidus; GOS, Glasgow Outcome Scale; GTTR, gross total tumor removal.
In the present series, the overall recurrence rate was of $51.7 \%$ ( 15 cases). On the other hand, the experience clearly emphasizes that when tumors are removed incompletely they tend to regrow, and the next surgeon operating on the patient will be confronted with severe adhesions of blood vessels and brain tissue. Even when GTTR is performed, tumor recurrence has been described to occur in 11.1 to $34 \%$ of cases. $5,10,14,15,18,20-22,30$ This might be explained by the presence of a microscopic residual tumor, which could not be detected in spite of meticulous inspection with the surgical microscope and neuroimaging. 5,6,9,10,13,25

There has been much concern about the potential impact of RT on growth and development and on performance in school and at home. The risk of neurologic complications such as vision loss or stroke is an additional concern. The possibility that RT could induce a secondary malignant neoplasm has also been an argument against its use, mainly in children under 2 years old. 7,30

In spite of the benign histology, $\mathrm{CP}$ can behave aggressively. ${ }^{4,10}$ The 10 -year overall survival is between $64 \%$ and $92.7 \%$, regardless of whether the tumor is treated in a surgically aggressive manner or with STR plus RT. 4,21,22 In our sample, the 10 -year overall survival was of $75.8 \%$.

Endocrine deficiencies are considered inevitable, and perceived as acceptable due to the current ability to provide

Table 4 Transcranial approach for resection of craniopharyngiomas

\begin{tabular}{|c|c|c|c|c|c|c|}
\hline Author/Year & Number of patients & $\begin{array}{l}\text { Mortality } \\
(\%)\end{array}$ & $\begin{array}{l}\text { GTTR } \\
\text { (\%) }\end{array}$ & $\begin{array}{l}\text { Recurrence } \\
\%\end{array}$ & $\begin{array}{l}\text { Complications } \\
\%\end{array}$ & $\begin{array}{l}\mathrm{F} / \mathrm{U}(\text { mean) } \\
\text { years }\end{array}$ \\
\hline Yaşargil et al ${ }^{2} 1990$ & 144 & 16.7 & 90 & 7 & $\mathrm{DI}-89.7$ & $\mathrm{~N} / \mathrm{A}$ \\
\hline Cabezudo et al ${ }^{10} 1991$ & 45 & 8.8 & 28.8 & 33.3 & $\mathrm{~N} / \mathrm{A}$ & 2 \\
\hline Hoffman et al 1992 & 50 & 2 & 90 & 34 & $\mathrm{DI}-100$ & 8.5 \\
\hline Gerganov et al ${ }^{8} 2014$ & 16 & 0 & 87.5 & 0 & 12.5 & $N / A$ \\
\hline Caldareli et $\mathrm{al}^{7} 1998$ & 52 & 3.8 & 77 & 19 & DI - 100 & 8.5 \\
\hline Fahlsbusch et al ${ }^{4} 1999$ & 58 & 12.8 & 45.7 & $18.7-51.2$ & 12.8 & 5.4 \\
\hline Sainte-Rose et al ${ }^{13} 2005$ & 66 & $\mathrm{~N} / \mathrm{A}$ & 50 & 36 & $\mathrm{~N} / \mathrm{A}$ & 7 \\
\hline Lena et $\mathrm{al}^{23} 2005$ & 47 & 2.4 & 33.3 & $\mathrm{~N} / \mathrm{A}$ & $\mathrm{N} / \mathrm{A}$ & 9.4 \\
\hline Elliott and Wishoff ${ }^{20} 2010$ & 26 & 0 & 77 & $33-67$ & 38 & 9.3 \\
\hline Mortini et $\mathrm{al}^{21} 2011$ & 112 & 2.7 & 71.6 & 24.5 & 26.6 & 6.9 \\
\hline Lynch et al (Present series) & 29 & 3.7 & 51.7 & 51.7 & $\mathrm{DI}-48.2$ & 7.1 \\
\hline
\end{tabular}

Abbreviations: F/U, follow-up; DI, diabetes insipidus; GTTR, gross total tumor removal; N/A, not available.

Table 5 Endoscopic approach for resection of craniopharyngiomas

\begin{tabular}{|l|l|l|l|l|l|l|}
\hline Author/Year & $\begin{array}{l}\text { Number of } \\
\text { patients }\end{array}$ & Mortality (\%) & GTTR (\%) & Recurrence (\%) & Complications (\%) & F/U Years \\
\hline De Divitis et al ${ }^{18} 2007$ & 10 & 10 & 70 & N/A & 20 & N/A \\
\hline Frank et al $^{29} 2008$ & 10 & 0 & 70 & N/A & N/A & 3 \\
\hline Gardner $^{28} 2008$ & 16 & 0 & 91 & 31.2 & N/A & 2.8 \\
\hline Leng $^{26} 2012$ & 24 & N/A & 75 & 0 & 34 & 9 \\
\hline Jane et al $^{19} 2010$ & 12 & 4.5 & 75 & 28.5 & 14.5 & 6.8 \\
\hline Cavallo $^{9} 2014$ & 103 & 1.9 & 68.9 & 22.3 & 15.2 & 4 \\
\hline Patel et al & & & \\
\hline
\end{tabular}

Abbreviations: F/U, follow-up; GTTR, gross total tumor removal; N/A, not available. 
hormone replacement therapy. ${ }^{4,5,13,22}$ In our sample, endocrine deficiencies were observed in $86.1 \%$ of the patients.

The lack of consensus regarding their optimal management and the potential morbidity of the treatment have led neurosurgeons to use alternative therapeutic modalities to obtain tumor control. Many authors have reported temporary beneficial effects of intracystic RT, intracystic interferon or bleomycin, which was used in one pediatric case. ${ }^{35-38}$ Our surgical objective was always to prioritize the patient's QoL; therefore, STR plus RT could represent a very acceptable goal in tumors encasing perforating vessels, or adhering to the hypothalamus. But RT is not without consequences, mostly in young children. When dealing with pediatric patients, we adopted a more conservative strategy that allows young patients to experience adequate psychological and motor development, and reduce the risk of postoperative hypothalamic obesity and a poor QoL. On the contrary, Elliott and Wisoff ${ }^{20}$ state that given the worse outcome in recurrent tumors in children and adolescent with giant tumors, the best chance for disease control and possible cure is radical resection at initial presentation.

\section{Conclusions}

The extended pterional craniotomy provides adequate access to $\mathrm{CPs}$, and when associated with meticulous microsurgery techniques, it enables GTTR even of extensive lesions. Gross total tumor removal can cure the patient, but is not always feasible because the lesion has invaded the hypothalamus or is involving perforating branches. Our surgical objective was always to prioritize the patient's QoL, so if the functional risk of GTTR outweighs its potential benefits, STR plus RT could represent a very acceptable goal. Good surgical results still depend on the surgeon's ability and experience to choose the best approach and interpret intraoperative risks in every single case.

\section{References}

1 Bunin GR, Surawicz TS, Witman PA, Preston-Martin S, Davis F, Bruner JM. The descriptive epidemiology of craniopharyngioma. J Neurosurg 1998;89(4):547-551

2 Yaşargil MG, Curcic M, Kis M, Siegenthaler G, Teddy PJ, Roth P. Total removal of craniopharyngiomas. Approaches and long-term results in 144 patients. J Neurosurg 1990;73(1):3-11

3 Teixeira Ribeiro JA, Plese JP, Marino Jr R. Tratamento dos craniofaringiomas por via transesfenoidal: resultados e seguimento pós-operatórios. J Bras Neurocir 2005;16(1):5-12

4 Fahlbusch R, Honegger J, Paulus W, Huk W, Buchfelder M. Surgical treatment of craniopharyngiomas: experience with 168 patients. J Neurosurg 1999;90(2):237-250

5 Hoffman HJ, De Silva M, Humphreys RP, Drake JM, Smith ML, Blaser SI. Aggressive surgical management of craniopharyngiomas in children. J Neurosurg 1992;76(1):47-52

6 Symon L, Sprich W. Radical excision of craniopharyngioma. Results in 20 patients. J Neurosurg 1985;62(2):174-181

7 Caldarelli M, di Rocco C, Papacci F, Colosimo C Jr. Management of recurrent craniopharyngioma. Acta Neurochir (Wien) 1998; 140(5):447-454

8 Gerganov V, Metwali H, Samii A, Fahlbusch R, Samii M. Microsurgical resection of extensive craniopharyngiomas using a fronto- lateral approach: operative technique and outcome. J Neurosurg 2014;120(2):559-570

9 Cavallo LM, Frank G, Cappabianca P, et al. The endoscopic endonasal approach for the management of craniopharyngiomas: a series of 103 patients. J Neurosurg 2014;121(1):100-113

10 Cabezudo JM, Vaquero J, Areitio E, Martinez R, de Sola RG, Bravo G. Craniopharyngiomas: a critical approach to treatment. J Neurosurg 1981;55(3):371-375

11 Fischer EG, Welch K, Shillito J Jr, Winston KR, Tarbell NJ. Craniopharyngiomas in children. Long-term effects of conservative surgical procedures combined with radiation therapy. J Neurosurg 1990;73(4):534-540

12 Al-Mefty O, Ayoubi S, Kadri PA. The petrosal approach for the total removal of giant retrochiasmatic craniopharyngiomas in children. J Neurosurg 2007;106(2, Suppl)87-92

13 Sainte-Rose C, Puget S, Wray A, et al. Craniopharyngioma: the pendulum of surgical management. Childs Nerv Syst 2005;21; (8-9):691-695

14 Minamida Y, Mikami T, Hashi K, Houkin K. Surgical management of the recurrence and regrowth of craniopharyngiomas. J Neurosurg 2005;103(2):224-232

15 Pang D. Surgical management of craniopharyngioma, in surgery of cranial base tumors. Seckhar LN and Janeka IP (eds) Raven pressNY1993:787-807

16 Samii M, Samii A. Surgical management of craniopharyngioma, in Schmidek HH (ed): Schmidek and Sweet. Operative Neurological Techniques: Indications, Methods, and Results, ed 4. Philadelphia, WB Saunders,2000:489-502

17 Kassam AB, Gardner PA, Snyderman CH, Carrau RL, Mintz AH, Prevedello DM. Expanded endonasal approach, a fully endoscopic transnasal approach for the resection of midline suprasellar craniopharyngiomas: a new classification based on the infundibulum. J Neurosurg 2008;108(4):715-728

18 de Divitiis E, Cappabianca P, Cavallo LM, Esposito F, de Divitiis O, Messina A. Extended endoscopic transsphenoidal approach for extrasellar craniopharyngiomas. Neurosurgery 2007;61; (5, Suppl 2):219-227, discussion 228

19 Jane JA Jr, Kiehna E, Payne SC, Early SV, Laws ER Jr. Early outcomes of endoscopic transsphenoidal surgery for adult craniopharyngiomas. Neurosurg Focus 2010;28(4):E9

20 Elliott RE, Wisoff JH. Surgical management of giant pediatric craniopharyngiomas. J Neurosurg Pediatr 2010;6(5):403-416

21 Mortini P, Losa M, Pozzobon G, et al. Neurosurgical treatment of craniopharyngioma in adults and children: early and long-term results in a large case series. J Neurosurg 2011;114(5): 1350-1359

22 Lee EJ, Cho YH, Hong SH, Kim JH, Kim CJ. Is the Complete Resection of Craniopharyngiomas in Adults Feasible Considering Both the Oncologic and Functional Outcomes? J Korean Neurosurg Soc 2015;58(5):432-441

23 Lena G, Paz Paredes A, Scavarda D, Giusiano B. Craniopharyngioma in children: Marseille experience. Childs Nerv Syst 2005; 21(8-9):778-784

24 Tomita T, McLone DG. Radical resections of childhood craniopharyngiomas. Pediatr Neurosurg 1993;19(1):6-14

25 Gonc EN, Yordam N, Ozon A, Alikasifoglu A, Kandemir N. Endocrinological outcome of different treatment options in children with craniopharyngioma: a retrospective analysis of 66 cases. Pediatr Neurosurg 2004;40(3):112-119

26 Leng LZ, Greenfield JP, Souweidane MM, Anand VK, Schwartz TH. Endoscopic, endonasal resection of craniopharyngiomas: analysis of outcome including extent of resection, cerebrospinal fluid leak, return to preoperative productivity, and body mass index. Neurosurgery 2012;70(1):110-123, discussion 123-124

27 Patel KS, Raza SM, McCoul ED, et al. Long-term quality of life after endonasal endoscopic resection of adult craniopharyngiomas. J Neurosurg 2015;123(3):571-580 
28 Gardner PA, Kassam AB, Snyderman CH, et al. Outcomes following endoscopic, expanded endonasal resection of suprasellar craniopharyngiomas: a case series. J Neurosurg 2008;109(1):6-16

29 Frank G, Pasquini E, Doglietto F, et al. The endoscopic extended transsphenoidal approach for craniopharyngiomas. Neurosurgery 2006;59(1, Suppl 1):ONS75-ONS83, discussion ONS75ONS83

30 Merchant TE, Kiehna EN, Sanford RA, et al. Craniopharyngioma: the St. Jude Children's Research Hospital experience 1984-2001. Int J Radiat Oncol Biol Phys 2002;53(3):533-542

31 Perneczky A, Reisch R. Keyhole approaches in neurosurgery. Vol 1. Concept and surgical technique. Austria: Springer; 2008: 37-83

32 Fatemi N, Dusick JR, de Paiva Neto MA, Malkasian D, Kelly DF. Endonasal versus supraorbital keyhole removal of craniopharyngiomas and tuberculum sellae meningiomas. Neurosurgery 2009;64(5, Suppl 2):269-284, discussion 284-286
33 Wilson DA, Duong H, Teo C, Kelly DF. The supraorbital endoscopic approach for tumors. World Neurosurg 2014;82(6, Suppl) S72-S80

34 Hoogenhout J, Otten BJ, Kazem I, Stoelinga GB, Walder AH. Surgery and radiation therapy in the management of craniopharyngiomas. Int J Radiat Oncol Biol Phys 1984;10(12):2293-2297

35 Julow J, Lányi F, Hajda $M$, et al. Further experiences in the treatment of cystic craniopharyngeomas with yttrium 90 silicate colloid. Acta Neurochir Suppl (Wien) 1988;42:113-119

36 Kobayashi T, Kida Y, Hasegawa T. Long-term results of gamma knife surgery for craniopharyngioma. Neurosurg Focus 2003;14(5):e13

37 Hukin J, Steinbok P, Lafay-Cousin L, et al. Intracystic bleomycin therapy for craniopharyngioma in children: the Canadian experience. Cancer 2007;109(10):2124-2131

38 Cavalheiro S, Dastoli PA, Silva NS, Toledo S, Lederman H, da Silva MC. Use of interferon alpha in intratumoral chemotherapy for cystic craniopharyngioma. Childs Nerv Syst 2005;21(8-9):719-724 